\title{
The Political, Socio-economic and Sociocultural Impacts of the King Abdullah Scholarship Program (KASP) on Saudi Arabia
}

\author{
Kholoud T. Hilal ${ }^{1}$, Safiyyah R. Scott ${ }^{2} \&$ Nina Maadad $^{3}$ \\ ${ }^{1}$ UNE School of Business, University of New England, Armidale, Australia \\ ${ }^{2}$ School of Education, University of Pittsburgh, Pittsburgh, USA \\ ${ }^{3}$ School of Education, University of Adelaide, Adelaide, Australia \\ Correspondence: Kholoud T. Hilal, UNE School of Business, University of New England, Armidale, NSW 2351 \\ Australia. Tel: 61-2-6773-5062. E-mail: ms.k.hilal@gmail.com \\ Received: January 14, 2015 \\ Accepted: February 15, 2015 \\ Online Published: February 16, 2015 \\ doi:10.5430/ijhe.v4n1p254 \\ URL: http://dx.doi.org/10.5430/ijhe.v4n1p254
}

\begin{abstract}
Since 2006, Saudi Arabian politicians, economists and sociologists have had to consider the implications of their country's King Abdullah Scholarship Program (KASP). Because Saudi Arabia has certain religious traditions and economic practices that are sensitive, international scholars are examining from different perspectives the outcomes and potential impacts of KASP. While Saudi Arabia has all the necessary tools to compete with the developed nations (such as natural resources and manpower), it is caught between the need to globalise its economy but retain its strict, conservative traditions. Following a brief definition of KASP, this paper highlights some of the external and internal contemporary political, economic and socio-cultural challenges that it sets for Saudi Arabia. Finally, the anticipated impacts of KASP according to scholarship recipients are reviewed using survey data from around 688 overseas Saudi students. This paper is based on the primary researcher's $\mathrm{PhD}$ thesis.
\end{abstract}

Keywords: King Abdullah Scholarship Program, Saudi Arabia, Internal and external challenges, Opportunities

\section{Introduction}

The consequences of sending Saudi students abroad are potentially profound because when they return they are doing so with new ideas and experiences that could undermine Saudi Arabia's protection of its centuries-old historical, religious and cultural identity (Denman \& Hilal, 2011). The bold initiative of the King Abdullah Overseas Scholarship Program is an important response to the internal and external challenges that Saudi Arabia is facing. Regionally, the Arab world is experiencing important and what might be considered, dangerous, political and social uprisings and changes (e.g., the civil wars and revolutions in Iraq, Tunis, Egypt, Syria, Yemen, and Palestine and Israel). These are alarming neighbouring countries, including the Gulf Cooperation Council (GCC), which includes Saudi Arabia, Kuwait, Qatar, Oman, Bahrain, and the United Arab Emirates. Internally, this sort of uprising in the Arab region pressures the government of Saudi Arabia to appease its citizens and carefully look after their needs in order to keep the situation under control. This includes issues pertaining to the annual incomes that Saudi citizens earn, the right to criticise the government, enhancing job opportunities, and promoting gender equity. Saudi Arabia also faces another sort of internal challenge involving its high youth population which can be a potential source of unrest if the youth are unsatisfied in terms of jobs, aspirations and cultural expression, etc. At the external level, Saudi Arabia has a vital role to play in the Middle East (Väyrynen, 1984) as it is anticipated to help resolve conflicts and promote peace in the region due to its geo-political significance and financial capacity. In terms of US-Saudi relations, Saudi Arabia has been working to improve its relations with the West especially after the 9/11 terrorist attacks on the World Trade Centre in New York in 2001 (Fawcett, 2013) where 15 of the 19 hijackers were Saudis.

A better higher education system which helps to develop the intellectual capacity of its citizens is seen by the Saudi government as the way to solve many of the issues facing KSA, especially if student mobility across the globe can be encouraged. This position reflects Saudi Arabia's view of education as helping to achieve a more skilled society so that it becomes an economic driver in the global knowledge economy. It is also a means to address broader societal issues and for this reason the KASP scheme is one strategy adopted to fulfil this vision. Given this scenario, this research investigates some key current political, economic and social challenges faced by Saudi Arabia. It also seeks 
to discover whether sending students abroad through KASP will help to address these challenges, or will have the potential to create more issues and problems, according to what KASP recipients themselves think.

This survey is the first of its kind and scale and unprecedented because it surveys more than 600 Saudi scholarship recipients, and addresses a critically important issue in an increasingly globalised education system. The huge significance of this study is derived from focusing attention on Saudi Arabia's unique culture and identity, the internal and external ramifications of the KASP scheme on Saudi Arabian politics, socio-cultural practices, and economic system.

The author of this paper is a recipient of a KASP award who approached her study from an 'insider' perspective. The insider's perspective is a tool used in qualitative research that offers an excellent opportunity to observe, record and analyse certain phenomena under study first-hand (Conrad, 1990; Holden, 2010; Kusow, 2003). In this sense, the 'insider' is usually more aware than the outsider about the context, in this case, Saudi Arabian culture including the internal political, economic and socio-cultural strengths and weaknesses. As the ethnographer, Kusow (2003), observed,

The perspective [of the insider] claims that outsiders cannot have the necessary sensibilities that can make, to borrow from Max Weber, verstehen, or empathetic understanding, possible because outsider ethnographers are not initiated in the cultural values of the people they study (p. 592).

Exercising the insider's perspective, or the 'worm's eye view', proved most helpful in understanding and interpreting meanings from the data collected. On the other hand, using an insider's perspective can have implications for the trustworthiness of the research findings because of possible researcher bias. To help offset this bias of the data analysis, this paper was written in conjunction with two scholars: firstly, an American researcher who studies the experiences of Saudi students in the US; and secondly, an Australian researcher who lived in the Middle East and her research interests are culture, education and language.

\section{Literature Review}

\subsection{Background and context of Saudi Arabia}

Saudi Arabia's longstanding history and global significance traces back to the $7^{\text {th }}$ century when Makkah (Mecca) was considered to be a central trading and religious gathering point, especially after Prophet Mohammad was chosen by God (Allah) to spread Islam. Although Saudi Arabia was only identified as the Kingdom of Saudi Arabia as recently as 1932, the roots of Islamic religion run deep and wide throughout the country. According to Denman and Hilal (2011), "the Islamic religion is considered as much a part of the Saudi identity as the country's longstanding history as part of the greater Arab Peninsula" (p. 304). Consequently, in a religion-based country like Saudi Arabia, Islam is instrumental in shaping and forming the national identity and different aspects of life such as lifestyle, education, culture, society and politics (Nevo, 1998). For this reason Saudi Arabia needs to be sure 'how to wield the stick' if it plans to reform and transform any or all of these aspects, while maintaining adherence to its religion and traditions.

\subsection{Contemporary internal and external political, economic and socio-cultural challenges in Saudi Arabia}

This research investigates some key current political, economic and social challenges faced by the KSA. It seeks to discover whether sending students abroad through KASP will help to address these challenges, or will have the potential to create more issues and challenges. The following lists represent some key internal and external political, economic and socio-cultural challenges for Saudi Arabia.

\subsubsection{Political Considerations}

- Saudi Arabia needs to reconsider and amend the immigrant labour laws in order to avoid clashes with their source countries. Saudi Arabia and the whole Gulf countries are less likely to pursue a common policy to manage immigration (Alkhathlan, 2000; Bahgat, 1999; GulfTalent.com, 2012).

- As the number of student graduates increase, it becomes very challenging for the government to provide every graduate with a job (Kapiszewski, 2006; The Economist Intelligence Unit, 2009a).

- The wars in Iraq have resulted in sectarian conflict erupting between Sunni and Shia Muslims. Since these two sects are also in Saudi Arabia, its government is concerned about policies that can maintain peace (Davis \& Hayashi, 2007; Gause, 1997; The Economist Intelligence Unit, 2009a).

- Due to the increasing population growth concentrated mainly in cities, the government of Saudi Arabia is under pressure to provide public services and infrastructure in order to satisfy the needs of its populations (Gause, 1994). 


\subsubsection{Economic Level}

- Saudi Arabia is anticipated to continue a strong market economy due to robust population growth, rising affluence in the region and ample natural resources. As a result, the region will continue to be an attractive destination for foreign investors. At the same time, the region's long-term economic expansion will critically depend on successful efforts to educate and employ the rapidly expanding youth population (Bahgat, 1999).

- The doors for women to enter the labour force are more welcoming than before and it is more likely that the number of working women will increase over the decade. Subsequently, businesses will face pressure to offer and provide more and more jobs to absorb these women workers (The Economist Intelligence Unit, 2009b).

- The rapid economic growth may result in mismatches between worker skills and available jobs. Disparities between expectations of salary and working conditions versus their reality may also be a potential source of discontent among workers. While ongoing education reforms will help, it is not anticipated that these mismatches will be solved within the next decade (Bahgat, 1999; The Economist Intelligence Unit, 2009a).

- Pressure exists from nationals who are demanding that the government of Saudi Arabia offer them job priority over foreign workers (Bahgat, 1999; Gause, 2002).

\subsubsection{Social Level}

- In general, the Gulf Arab region is one of the fastest-growing populations worldwide. It is estimated that by 2020 , this population will increase by one-third to around 53 million people. The majority of this population will be under 25 years of age. Although this rapid growth and expanding youth population presents major opportunities, it presents serious challenges for all Gulf governments including Saudi Arabia (Barber, Mourshed, \& Whelan, 2007; Gause, 1997)

- The identity, social attitudes and norms of young Saudis has the potential to be influenced by more access to education, international media, and new digital/online technologies (Barber et al., 2007; Davis et al., 2007).

- The Saudi overseas scholarship program will result in students returning with new ideas, thoughts and behaviours that may conflict with existing Islamic and cultural practices (GulfTalent.com, 2012; The Economist Intelligence Unit, 2009b).

\subsection{King Abdullah Scholarship Program}

In 2005, the government of KSA launched the largest student overseas program worldwide - the King Abdullah Scholarship Program (KASP) (Bukhari \& Denman, 2013). This program was intended to run for one year only, with the USA as the only destination for Saudi students (Ottaway, 2012). Nevertheless, based on his 2012 announcement, the Minister of Higher Education, Dr. Al-Ankari, announced that it would continue until 2020 (Ministry of Higher Education, 2014). Originally, the number of overseas Saudi students who were sponsored by KASP was approximately 9,000 in 2006 and rose to 140,000 Saudi students by 2012 (Zeigler, 2012). More recently in 2014, the number rose to 185,000 KASP recipients (Ministry of Finance, 2014). This represents a 20-fold increase and is indeed, significant.

KASP recipients receive full university tuition coverage, allowances for materials and a monthly stipend for living expenses. They also receive complete medical and dental insurance and annual round-trip airfare vouchers for themselves and their families. Students also receive rewards for high grade point averages, for papers published, as well as the publishing of research. To ensure a representative student population studying abroad, scholarship recipients vary from the privately educated elite of larger cities in Saudi Arabia to the youth from poorer, smaller towns (SUSRIS, 2012).

The mission, vision, and goals of the King Abdullah Scholarship Program as expressed by the Ministry of Higher Education (2014), are included in Figure 1. 


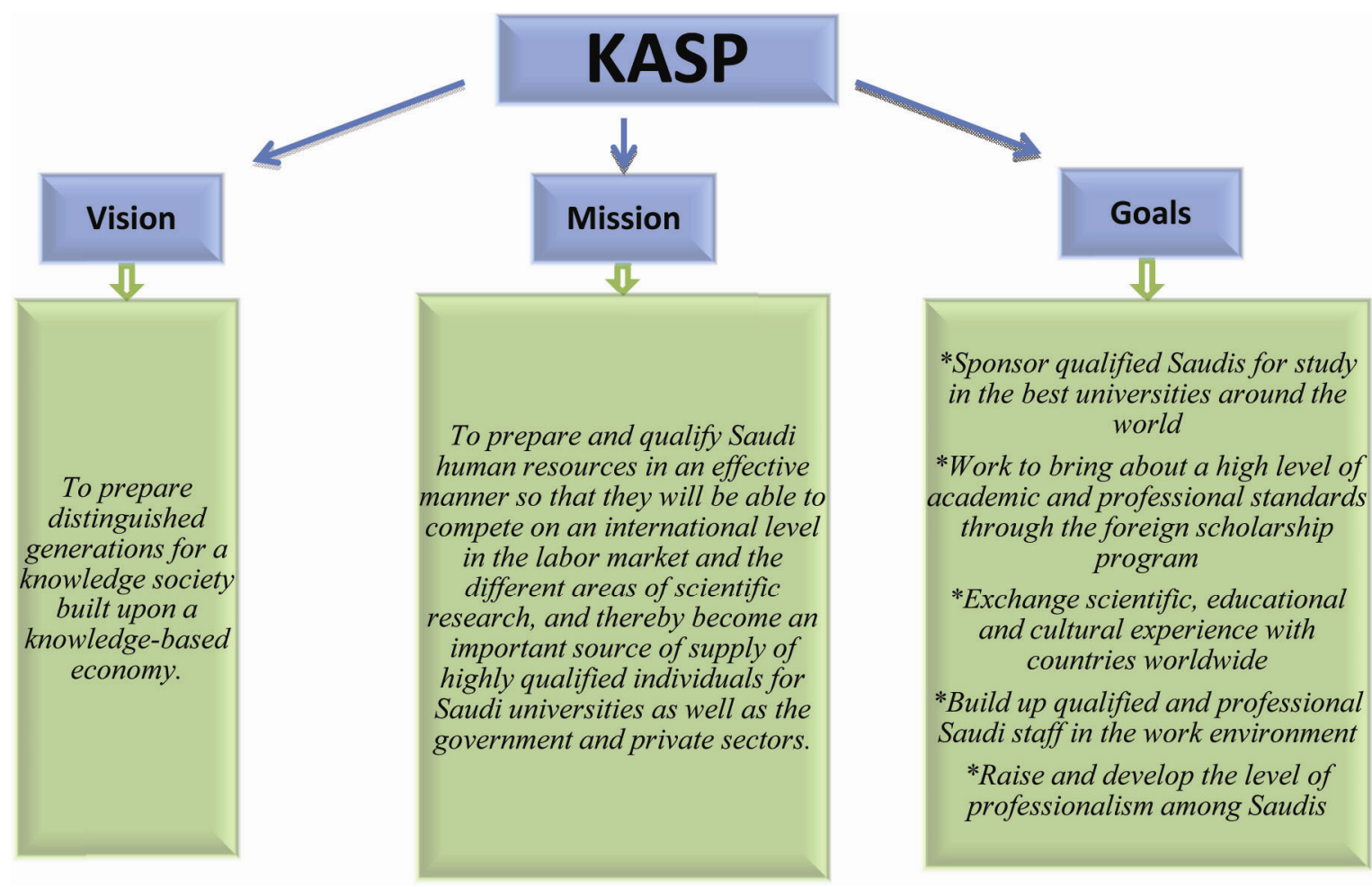

Figure 1. KASP Mission, Vision and Goals from the Ministry of Higher Education (2014)

\subsection{Reasons for establishing the KASP scheme}

King Abdullah Bin Abdul Aziz started an "educational revolution" by significantly increasing the numbers of private and public universities and colleges in Saudi Arabia (Meo, 2012). Needless to say, the most substantial example of his awareness of the importance of a solid education system is the King Abdullah Scholarship Program (KASP). However, the real reason/s and motives for launching this unique scholarship program have not been very explicit. The literature and available data suggest three possible reasons why this was the case. However, before presenting these reasons, it is important to bear in mind that while this study continues to separate the political, economic, and socio-cultural impacts of KASP, in many cases those three aspects overlap (as it will be noted throughout the study). For example, it is argued that socioeconomic change always leads to political change eventually and indirectly; and that economic changes increase the likelihood of social changes because it affects the political culture (Mitchell, 2010). For this reason, the emphasis of this research is on the implications of these issues on the wider Saudi Arabian society.

\subsubsection{Reason 1: The political context}

There is a strong link between the foundation of KASP and the 9/11 terror attacks on the United States in 2001. The ramifications of 9/11 for Saudi Arabia persist to this day as 15 of the 19 hijackers were Saudis. After the attacks, more restrictions were placed on issuing visas to Saudi students going abroad, especially to the United States. For Saudis, "the open door for Saudi students slammed shut in 2001" (Knickmeyer, 2012, para. 39). The 2004-2005 academic year saw a dramatic decrease in Saudi students with only about 3,000 Saudis studying in the US, down 54.7\% from the 2001-2002 school year (Institute of International Education, 2014). Consequently, American universities lost around $\$ 40$ million a year in tuition fees from Middle Eastern students after 9/11 (Knickmeyer, 2012). Saudi students also endured discrimination, social anxiety, verbal as well as physical assault, and emotional upheaval due to negative media representation post 9/11 (Batterjee, 2010). This discrimination against Arabs/Muslims, particularly Saudis, took different forms. For example, Sami Al-Obeid's U.S. visa was revoked without explanation, and he could not finish his U.S. degree (Knickmeyer, 2012).

Four years after 9/11, King Abdullah bin Abdul-Aziz was proclaimed the sixth King of the Kingdom of Saudi Arabia on $1^{\text {st }}$ August 2005. Accordingly, in 2005 and 2006, he visited many influential countries for the purpose of improving international relations between Saudi Arabia and the rest of the world (Heyn, 2013; Royal Embassy of Saudi Arabia in Washington DC, 2013). As part of this strategy, in 2005, King Abdullah visited the United States 
and met with President George W. Bush, persuading him to reopen the student visa service for Saudi students. The king argued that the "education" program was crucial for the Saudi-U.S. long-term relationship (Knickmeyer, 2012). Ultimately, the meeting between King Abdullah and President Bush resulted in KASP, which boasts the world's largest overseas scholarship program (Bukhari \& Denman, 2013). It was reported that KASP was established mainly to help Saudi Arabia rebuild its international relationships with the West after the 9/11 attacks (Knickmeyer, 2012; Thomas, 2013). Elsewhere the KASP scheme has been described as a tool for peace (Hilal \& Denman, 2013), and as a strategy to transform barriers between cultures into bridges (Denman \& Hilal, 2011).

\subsubsection{Reason 2: The economic context}

Most studies tend to assume that the main reason for founding KASP had an economic basis. Specifically, the Ministry of Higher Education in Saudi Arabia (2014) had stated that the mission of KASP is:

To prepare and qualify Saudi human resources in an effective manner so that they will be able to compete on an international level in the labor market and the different areas of scientific research, and thereby become an important source of supply of highly qualified individuals for Saudi universities as well as the government and private sectors. (para. 1)

Bukhari and Denman emphasize the importance of the KASP scheme because "overseas study is considered for a nation that is in need for skilled Saudi nationals" (2013, p. 151). Moreover, Prof. Abouammoh (2010), in discussing the moves to reform the higher education system in Saudi Arabia, believes that KASP is one of the key strategies that will lead to economic prosperity and solve the high rate of unemployment in Saudi Arabia. The Center for Higher Education Research and Studies (CHERS) in Saudi Arabia adds that, "the scholarship is restricted to discipline[s] mostly needed by the Saudi labor market such as medical studies, engineering and business" (Mazi \& Abouammoh, 2009, p. 14).

Based on the mission and vision of KASP, some scholars perceive KASP to be a strategy for "promoting a transition to a knowledge economy" (Gallarotti, 2013, p. 1). Bin Taleb (2013) contends, "Aspects of controlling the financial boom and directing it in a way to support the economy and build society is manifested in the massive scholarship programs..." (pp. 22-24). He goes on to argue that:

The extent to which education helps in achieving the economic development depends on the standard and the quality of education and because scholarships for studying abroad is one of the educational areas which provide distinguished and sophisticated standard of education that contributing to the development of the cultural and educational standard on society. The economic return will undoubtedly be great. (2013, p. 27)

These are the kinds of arguments made to suggest that KASP is a strategy created for economic reasons.

\subsubsection{Reason 3: The socio-cultural context}

In order to effect changes in government policies that guide education and socio-cultural customs and traditions, government decision-makers need to be confident that the wider society will accept these changes otherwise the risk of failure could be high. Saudi Arabia is a deeply religious and conservative society, and therefore any change or reform would necessarily take time until the people learned to tolerate and accept change. In research conducted by Clary and Karlin (2011), a story was reported concerning a discussion between King Fahd (the ruler prior to King Abdullah) and King Abdullah. King Fahd referred to the huge improvements that Saudi Arabia had achieved, and how the nation had transformed from desolate deserts into a wealthy, modern country. King Fahd, however, believed that changing the country was easy, but changing the Saudis' way of thinking seemed impossible. Six years later, King Abdullah proved that changing the rigid ways of thinking among Saudis is possible after considering and embracing deliberate policies to stimulate societal reform (Clary \& Karlin, 2011; Ottaway, 2012). King Abdullah is thus seen as reform-minded within the Saudi context (BBC News Middle East, 2013).

Scholars such as Ottaway (2012) have asserted that many Saudis presume that King Abdullah's secret objective in starting KASP was to create a critical mass of reform-minded Saudis who will eventually form a pressure group sufficiently powerful to untie the rule and influence of the ultra-conservative "Wahhabi" religious establishment over Saudi society. In this way, King Abdullah is seen as increasing the pace of change (Ottaway, 2012). Coleman (2012) adds, ".... in fact, part of the rationale of the [KASP] program is to make Saudi Arabia a more open society" (para. 4). Coleman also mentions the importance of the internal scholarship program, but she believes that its recipients will miss out on the more substantial benefit offered by the overseas scholarships, namely that people will be exposed to more open societies (Coleman, 2012). Bashraheel in the Saudi Gazette (2013) states that it is 
hoped that KASP's graduates will bring social change and create a more open society as that is one of KASP's goals.

\subsection{The risk of "brain drain" associated with student mobility for countries of origin}

Despite the numerous benefits of overseas scholarship programs, various governments that encourage and support students to study abroad face a number of risks in doing so. First of all, Altbach (2004, p. 12) revealed that $80 \%$ of international students move from developing countries to developed countries - a situation that can cause problems for developing countries. Developed countries are currently experiencing skilled workforce shortages and rapidly decreasing and aging populations. To overcome this they attract skilled international students after their graduation to work in key economic sectors in order to remain competitive in a more globalised economy (Commander, Kangasniemi \& Winters, 2004; Dustmann, 2007; Verbik \& Lasanowski, 2007). As a result, many of these international students find jobs in their host countries and do not return to their countries of origin (Altach, 2004; Tremblay, 2002). For example, after interviewing 273 Chinese students in the United States, only less than $9 \%$ of those interviewed wanted to return to China. Indeed, 50,000 Chinese students became permanent residents of the United States; with 10,000 working in Canada and in Australia, more than 20,000 Chinese students were permitted to stay in foreign countries. However, the longevity of that commitment is somewhat in doubt (Zweig, 1997).

Moreover, Baas (2006) declared that the propensity for international students who seek permanent residency (PR) in their host countries after finishing their degrees is now noticeably high. More specifically, 33\% of those international students who completed their studies in 2003 obtained a PR visa under the onshore overseas student visa subclasses. Baas (2006) clarifies that the origin countries of those students were all South Asian (e.g., Pakistan with 67\%; Bangladesh with 71\%; India with 73\%; and Nepal with 77\%) and that nearly three quarters of Indian students, who finished their courses in 2003, obtained their PR visas and remained in Australia. In the United States, approximately $50 \%$ of European doctoral graduates stay there after they finish their studies and many do not return home at all (Mahroum, 1999; Straubhaar, 2000). Because of this situation, countries of origin are seen to be wasting money sponsoring those students, especially as these countries are deprived of the benefits when their own students graduate and do not return from overseas (Tremblay, 2002).

The phenomenon of many overseas students preferring to stay and live in the host countries, is referred to as 'brain drain'. According to Commander et al. (2004), 'brain drain' is a term referring to the movement or migration of personnel with technical skills or knowledge from developing countries to developed countries. In the students' scenario, brain drain is acquiring new skills and choosing to stay in the host countries following the completion of their degrees. In this sense, Tremblay (2002) sees that "student flows represent a form of migration of qualified labour" (p. 42). This migration of skilled individuals typically leads to a distortion of the labour market in the countries of origin and in turn reduces the remaining population's standard of living. Solimano (2008) sees these downsides for poor economies in the following way:

From a global perspective these policies of attracting talent by affluent economies compete with the efforts of developing countries and poor economies to retain its internal talent or attract it from other nations, to cover internal skills shortages, from other countries. (p. 10)

An example of this can be seen in the healthcare sector where brain drain worsens the already depleted healthcare resources in some developing countries. This occurs especially in Africa, and increases the gap in health inequities worldwide (Pang, Lansang \& Haines, 2002). Furthermore, since the developed countries usually have better facilities, more job opportunities, more leisure and better lifestyles than the countries of origin or sending countries (Feng, 2001; Inglehart, Foa, Peterson \& Welzel, 2008), students returning to their home countries are more sensitive to what their countries of origin lack compared to developed/host countries. Consequently, this situation can result in people having less loyalty to their countries of origin (Baruch, Budhwar \& Khatri, 2007, p. 103), loss of their national identity or connection (Rizvi, 2005) and becoming involved in political instability.

Finally, on the risks of 'brain drain', Commander et al. (2004) argue that,

Overall, our conclusion has to be that while there is clearly a possibility that the brain drain is beneficial to the residents left behind in the home countries, there are reasons - some of them of recent origin - to be suspicious of that conclusion. It is not even certain that there is an overall global welfare gain from the brain drain, although given the apparently large private benefits of the migrants themselves and their higher productivity in their new locations, it seems highly likely. (p. 266)

Unfortunately, there is a dearth of research that can shed more light on how this may affect Saudi Arabia. Saudi 
Arabia has a much higher per capita income than countries and regions mentioned in research concerning brain drain (e.g. South Asia, China, Africa), which could possibly indicate that higher income and better standard of living in Saudi Arabia may offset the potential for brain drain. That being said, standard of living is relative. If Saudis perceive that host countries offer better lifestyles and job opportunities than what remains back home, the risk of brain drain is still relevant. The contemporary internal and external political, economic, and sociocultural challenges facing Saudi Arabia such as those mentioned in section 2.2 illustrate that serious challenges remain back home.

The next part will present the participants' perspectives regarding the possible positive or negative impacts of King Abdullah Scholarship Program. The mission, vision and goals of the KASP scheme are clearly aimed to contribute to these major reforms and to help address many of the deficiencies of Saudi Arabia's higher education system.

\section{Methodology}

The survey used in the study was an on-line instrument that sought biographical information about Saudi students studying outside the KSA, together with their perceptions of the present and future benefits of international study to themselves and their country. Two pilot studies were conducted with small student samples to test and refine the instrument before it was distributed to 1000 Saudi students studying outside their homeland. Except for biographical information, items on the survey required responses on a five-point Likert scale. The Statistical Package for the Social Sciences (SPSS) was used to analyse the findings. A copy of the survey can be found in the appendix of this paper.

\subsection{Research hypotheses and statistical tests}

The following research questions were posed in order to address the problem under investigation.

1. What are the major strengths and weaknesses of the King Abdullah Scholarship Program?

2. What benefits has the KASP scheme brought to recipients and KSA?

3. To what extent has the emphasis on student mobility been successful based on KSA's goals?

4. What major challenges and issues have surfaced that need to be addressed?

5. What policy or other initiatives are needed for improving the efficacy of the Program?

6. What social, political and economic tensions are emerging following the implementations of the KASP scheme?

3.2 The sample

Bartlett, Kotrlik and Higgins (2001) provide a method for calculating the appropriate sample sizes for survey research. Using this method, the appropriate sample size for surveying a population of 130,000 (the approximate number of Saudi students sponsored by KASP) is 383 for a confidence level of $95 \%$ and 662 for a confidence level of $99 \%$. The on-line survey for this study was distributed to a random sample of 1000 Saudi international students, with 688 students returning completed surveys, constituting a response rate of $68.8 \%$. It is reasonable to assert, therefore, that the random sample used for this study is representative of the general population of Saudi scholarship students, at a confidence level of $99 \%$.

Characteristics of the sample included:

- 374 students (54.4\%) were married and 314 (45.6\%) either unmarried or divorced;

- $68.2 \%$ of the sample had one or more children;

- 303 respondents (44.0\%) were studying in the United States, 227 (33.0\%) in Australia, $65(9.4 \%)$ in the United Kingdom, and 28 (4.1\%) in Canada. Other countries in which small numbers of respondents were studying included Austria, China, Czechoslovakia, France, Germany, Ireland, New Zealand, South Korea and Sweden.

- 215 respondents (31.3\%) were in their first year of international study, $122(17.7 \%)$ were in their second year of international study, with the remaining $351(51.0 \%)$ in their third or subsequent year of international study; and

- 202 respondents (29.4\%) were enrolled in Engineering, 191 (27.8\%) in Business/ Economics/ Accounting/ Finance, 101 (14.7\%) in Computing Science, and 53 (7.7\%) in Medicine. Other disciplines represented in the sample included Medical Science, Mathematics, Health Sciences, Nursing, Pharmacy and Law. 


\section{Findings}

It is important to bear in mind that while this paper categorises the anticipated impacts of KASP in political, economic, and socio-cultural levels, this section shows that in many cases these three variables overlap and are difficult to separate. However, survey results will be categorised into these three broad realms for the purposes of data analysis and discussion.

Table 1. Summary of the Political, Economic, and Socio-cultural impacts of KASP according to KASP recipients

\begin{tabular}{|c|c|c|c|}
\hline Impacts of KASP & KSA Politics & KSA Economics & KSA Socio-culture \\
\hline Benefits & $\begin{array}{l}\text { 1) Improve KSA's } \\
\text { image after } 9 / 11 \\
\text { 2) Improve living } \\
\text { standards }\end{array}$ & $\begin{array}{l}\text { 1) Skilled Saudi workers } \\
\text { 2) Reduce unemployment of } \\
\text { Saudis } \\
\text { 3) } 46 \% \text { believed that KASP } \\
\text { would reduce the number of } \\
\text { foreign workers }\end{array}$ & $\begin{array}{l}\text { 1) Saudis as more } \\
\text { open-minded } \\
\text { 2) Saudis as globally } \\
\text { competent } \\
\text { 3) Higher standard of living } \\
\text { 4) Competency in the English } \\
\text { language }\end{array}$ \\
\hline Risks & $\begin{array}{l}\text { 1) Brain drain with } \\
79 \% \text { of overseas Saudi } \\
\text { students willing to } \\
\text { extend their stay abroad }\end{array}$ & $\begin{array}{l}\text { 1) Not offering enough job } \\
\text { opportunities } \\
\text { 2) Inability to manage the } \\
\text { high expectations of } \\
\text { returned students who want } \\
\text { high positions with large } \\
\text { salaries }\end{array}$ & $\begin{array}{l}\text { 1) Loss of cultural and } \\
\text { national identity }\end{array}$ \\
\hline
\end{tabular}

4.1 Impacts of KASP from a political dimension

4.1.1 Improvement in living standards

The survey results indicate that the students expect improvement in living standards as a result of KASP. Survey Q. 16 shows that of 556 students, $434(78 \%)$ believed that KASP would result in a higher standard of living which will facilitate general improvement country wide. It is important to note that in 2014 Saudi Arabia was categorised as a High-Income non-OECD country by the World Bank (2014) and placed in the Very High Human Development category of the Human Development Report by the United Nations Development Programme (2014). This shows that Saudi Arabian citizens already enjoy many benefits of a highly developed nation but survey results indicate more improvement is expected. This data also indicates a belief in education as a means for raising a nation's standards. Optimism for higher standards of living can be a benefit when combined with real outcomes; however, it can serve as a challenge if the country does not meet the high expectations of its returning graduates which, in turn, could lead to political and social unrest.

\subsubsection{Reputation/Stereotype}

As mentioned previously, KASP was conceived following a meeting between King Abdullah and President Bush after 9/11 to reopen Saudi student visas to the US and help rebuild international relations between Saudi Arabia and the West following the terrorist attacks (Knickmeyer, 2012; Thomas, 2013). As cultural ambassadors, when students were asked about how they would attempt to improve their country's cultural/national stereotype, results indicate that hundreds of students are willing to help correct the stereotype (Survey Q. 11). Ways to help correct negative stereotypes included: communicating with Westerners; trying to change the way they feel about Islam; showing more respect to them; and promoting greater equality and peace. Each response was supported by at least 200 students. 


\subsubsection{Risk of Brain Drain}

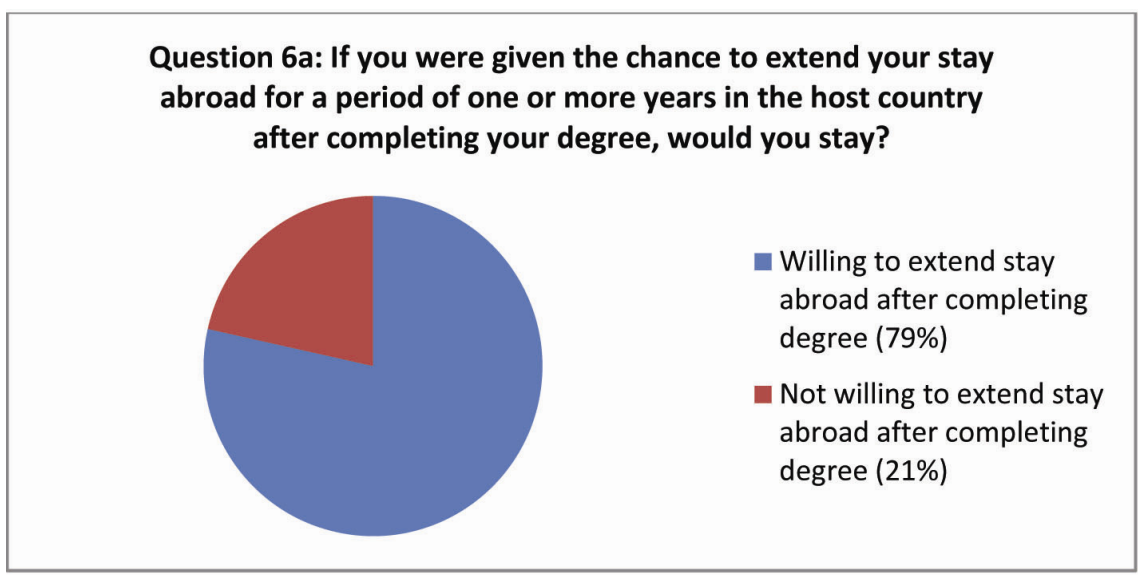

Figure 2. Results of Question 6a - Willingness to extend stay abroad after studies

As discussed in the risks section, a potential major challenge when a country invests in education abroad for its citizens is the risk of brain drain, i.e. when overseas students prefer to stay and live in the host countries, thereby depriving the country of origin of its human capital. The survey data indicates that 464 students (79\%) were willing if given the chance - to extend their stay in the host country for one or more years after the successful completion of their degrees (Q. 6a), as shown in Figure 2. In a follow-up question, participants were asked to choose the reasons they desired to extend their stay abroad by checking all that apply. The results are illustrated in Figure 3.

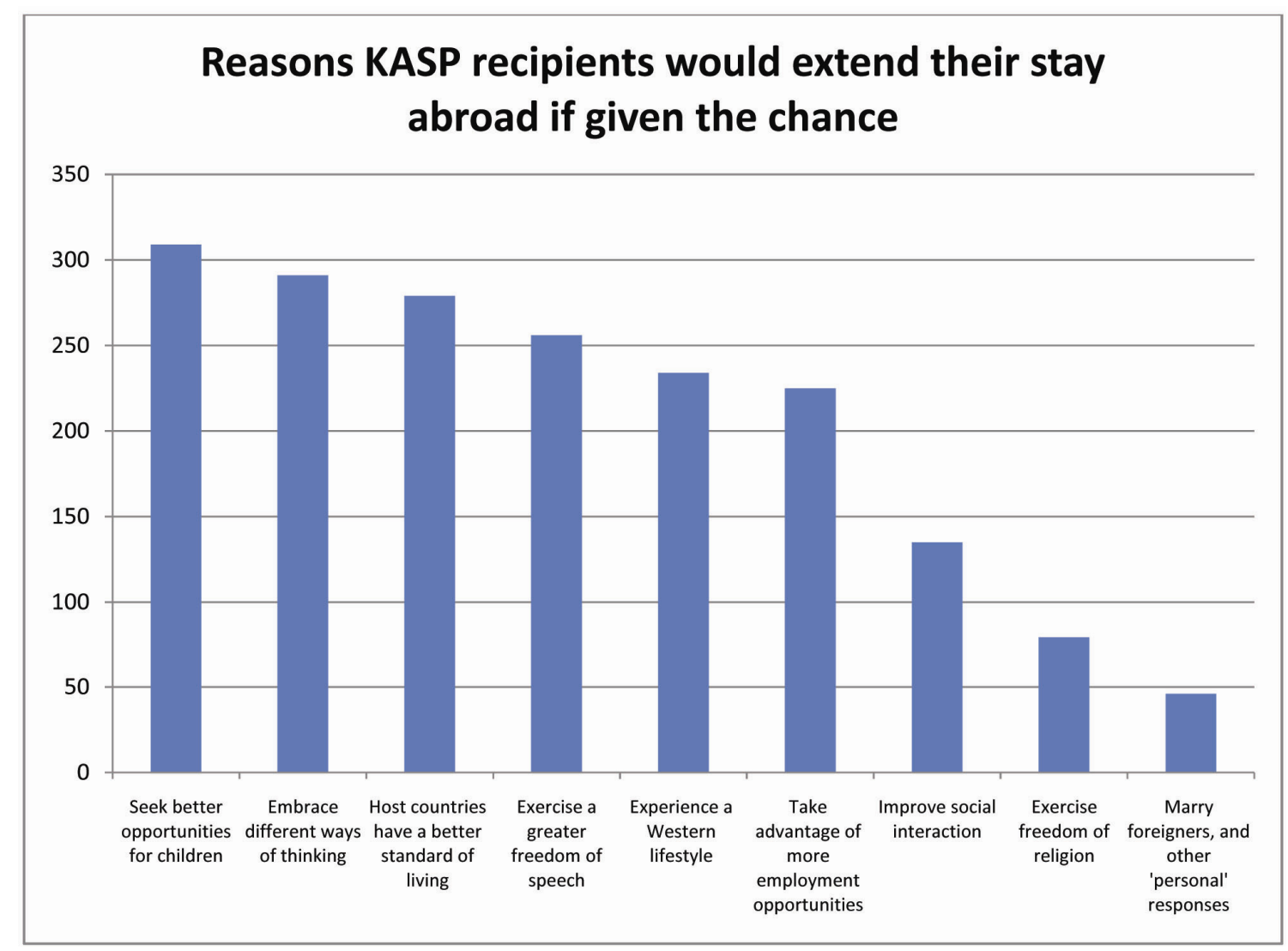

Figure 3. Frequency of reasons chosen for extending stay abroad if given the chance (Question 6b)

The most frequently chosen reason students desired to extend their stay abroad was to seek better opportunities for their children. This explanation coupled with responses such as "host countries have a better standard of living" point to the risk of brain drain. When students feel the host country has better employment opportunities, standard of living, and the ability to exercise greater freedoms than in their own country, the desire to yield greater reward for their hard earned credentials could lead to KASP recipients trying to stay in the host country. The risk of brain drain can be 
particularly problematic for Saudi Arabia whose citizens are studying at their government's expense rather than being self-funded. This runs the risk of KSA losing more than human capital but financial investment as well.

Further research is necessary to specify and identify the length of the extensions the students would seek (i.e. days, months, years, or indefinitely) or in what capacity they wish to stay (i.e. visitor, worker, researcher, etc.).

\subsection{Impacts of KASP from an economic perspective}

\subsubsection{Labour Force}

As discussed in the political impacts section, $78 \%$ of respondents believe that a higher standard of living will result from KASP, indicating a better educated and more skilled workforce will translate into improved sector-wide outcomes. In terms of reducing the number of foreign workers due to a more skilled Saudi workforce (Q. 7), the responses were mixed and therefore inconclusive. This question may have been confusing due to the lack of clarity on roles and definition of skilled and unskilled labour. It was hoped that this question would have yielded answers concerning skilled workers, as it is believed that the Saudi government has made a concerted effort to diversify the workforce and to decrease its dependence on skilled foreign labour. Further research on this matter is needed.

\subsubsection{Jobs}

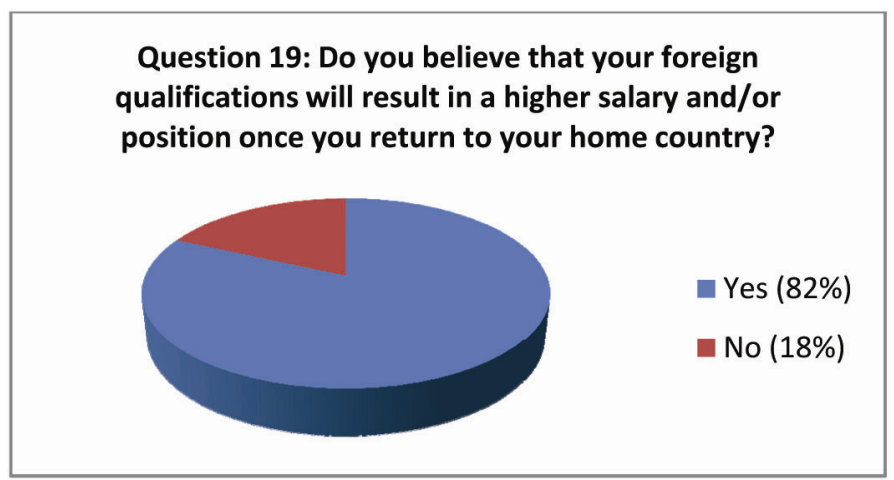

Figure 4. Results of Question 19 - Belief that foreign qualifications will yield higher salary and/or position upon return to home country

Survey results indicate that $82 \%$ of students believe that their foreign qualification will result in a higher salary and/or position when they return to their home country (Q. 19). This high percentage may pose a serious challenge for the government if they are not prepared to absorb the huge numbers of returning graduates. Large numbers of unemployed or underemployed KASP graduates could create dissatisfaction and unrest among returnees given the high percentage of those expecting higher salary and/or higher position upon their return. Meeting the expectations of higher salary and/or position could also be instrumental in offsetting the potential for brain drain or have the opposite effect of furthering it if expectations are not met.

\subsection{Impacts of KASP on the socio-cultural level}

\subsubsection{Educated, Global Citizens}

In addition to the anticipation that KASP will yield better educated, more skilled citizens and an overall higher standard of living for the country, respondents also indicated that a primary benefit from KASP is to know different cultures. Survey Q1 stated: "Studying abroad is a great opportunity for me in terms of providing better standard of education and knowing different cultures." Out of 616 responses, the overwhelming majority strongly agree with 444 responses: 151 students agree; 15 were neutral; 4 disagree; and 2 strongly disagree.

Responses to survey Q12, as shown in Figure 5, also illustrate that KASP participants are seeking both academic qualifications and global competencies. Objectives for studying abroad included: expand their worldview; learn a different or expanded way of thinking; and discover the world. Furthermore $74 \%$ of respondents revealed that learning a different language is a strong motivation for studying abroad. With $97.5 \%$ of respondents studying in English-speaking countries, fluency in English which is the modern world's lingua franca is an anticipated benefit of KASP. The survey results indicate that students anticipate not only benefitting from a quality education, but becoming well-rounded global citizens with international competencies and English fluency so that they can compete in a global knowledge economy. 


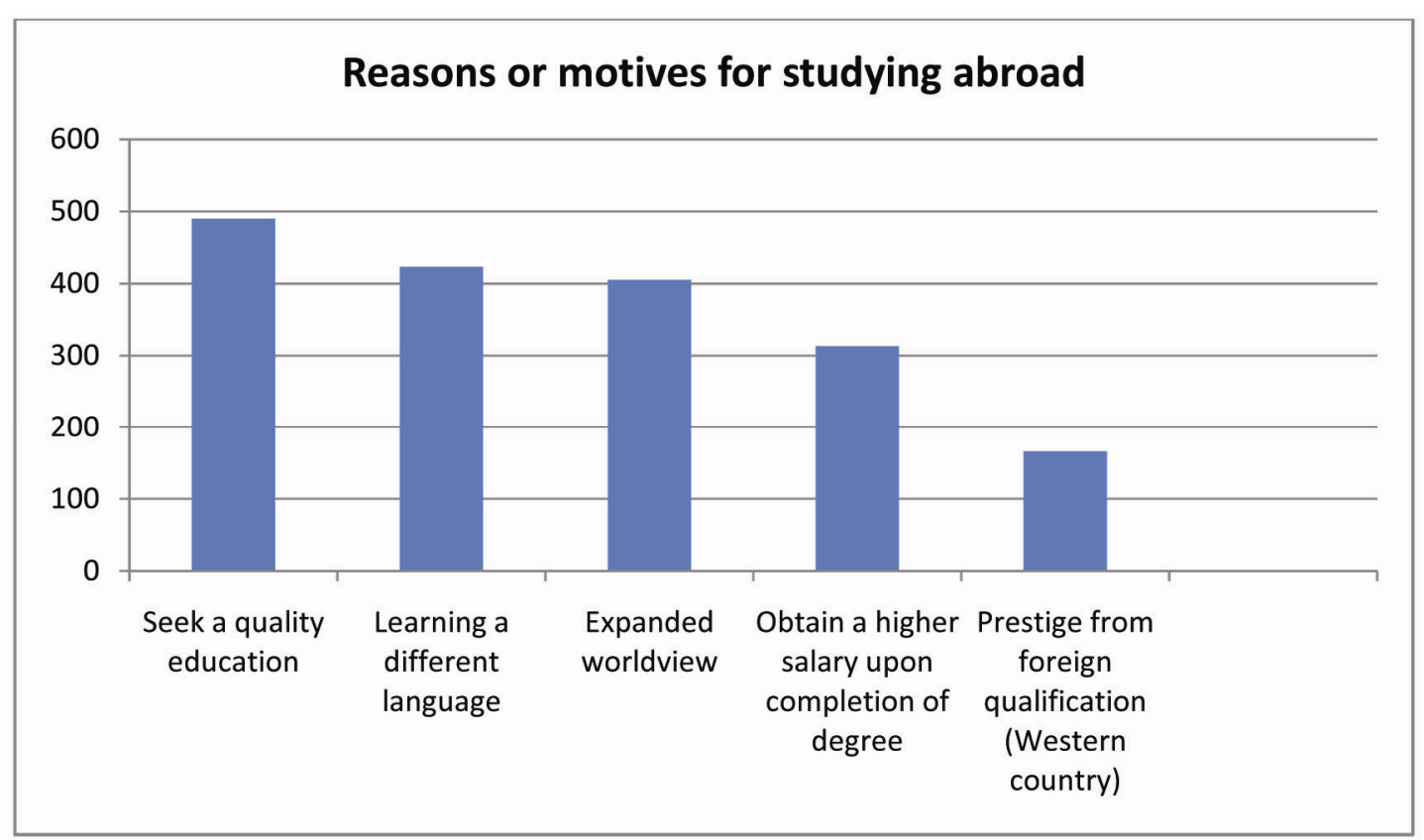

Figure 5. Reasons or motives for studying abroad (Question 12)

\subsubsection{Culture and Identity}

In Q2 of the survey, 63.3\% of students did not agree that increased interactions with people coming from different religions and backgrounds in the host countries would affect their cultural identity. However, in survey Q14 (“As countries like Saudi Arabia and UAE are sending more and more students abroad, you are of an opinion that you believe that your/their national and cultural identities will remain intact") respondents' answers were: 54 strongly agree; 138 agree; 160 are neutral; 176 disagree, and 33 strongly disagree. Saudi students seem to deny that studying overseas may affect their cultural and Islamic identities when the question is asked personally or in a direct way but the results are inconclusive when asked about the overall national and cultural identity. While the data collected remains inconclusive, it appears that Saudi students demonstrate levels of self-confidence when pursuing study abroad for their own personal growth, but have, at the same time, expressed doubt as to how study abroad - as an aggregate whole for the nation - will benefit (or threaten) the identity of the country. It is clear that further research is necessary to better understand differences of opinion.

\section{Conclusion}

The largest fully-endowed scholarship program ever established by a nation state (Bukhari \& Denman, 2013) has huge implications for Saudi Arabia and the rest of the world. The external and internal contemporary political, economic and socio-cultural considerations as a result of the King Abdullah Scholarship Program are complex and require dedicated research to understand these implications and outcomes. To explain these implications, KASP recipients were surveyed regarding the potential benefits and challenges for themselves and their country. It is clear that they anticipate being better educated, more skilled and globally competent, and expect a higher standard of living to result from this scholarship initiative. However, it is unclear as to whether or not Saudi Arabia will be able to meet these expectations. This uncertainty is reflected in the data showing that a high percentage of respondents wish to extend their host country stay on the completion of their studies, citing better opportunities for their children and a higher standard of living among the top three reasons. Such a bold initiative and investment by the Saudi government could cause problems if the students' high expectations upon graduation are not met especially after having experienced a better standard of living abroad (according to many of the participants). Failure to meet these high expectations could have negative implications for Saudi Arabia such as human capital flight (i.e. brain drain) and political and social unrest. Additionally, it is unclear as to whether the students believe that KASP may potentially impact the national and cultural identity of Saudi Arabia since the results proved inconclusive. This fascinating and intriguing finding begs for additional research to explain this split in thinking so as to understand the implications and outcomes of study abroad on this culturally conservative group.

Nearly ten years beyond the inception of KASP, long-term research on the implications and outcomes of KASP for Saudi Arabia and the rest of the world are long overdue. Given the dearth of research so far, further analysis is 
required in a variety of areas pertaining to the experiences of over a 100,000 Saudis studying abroad, and what the implications are for Saudis and non-Saudis alike.

Last but not least, King Abdullah bin Abdul Aziz, hailed as a reformer and visionary by many, passed away a few weeks before the publishing of this paper. The new ruler, King Salman, has already implemented changes in the government such as joining the Ministry of Education and the Ministry of Higher Education into one ministry.

Change in leadership raises many questions for the future of Saudi Arabia in general and the Scholarship Program in particular. Will the scholarship program even continue beyond this year? Would the unifications of ministries affect the standard of the overseas scholarship programs and the tertiary level in general? These recent changes open doors for future researchers to examine the impact/s of King Abdullah's death, the current governmental changes such as the joining of the ministries and the future changes that may yet result from the direction of the new king.

\section{References}

Abouammoh, A. M. (2010). Higher education in the GCC states: Reforms and regulations. Retrieved from http://faculty.ksu.edu.sa/abouammoh/Workshops/ABOUAMMOH\%20AL\%20JISR\%203RD\%20WORKSHOP \%20JUNE\%2069\%202010\%20DUBAI\%20UAE_SH\%20edited\%20version.pdf

Al-Khathlan, S. M. (2000). Saudi foreign policy towards central Asia. Retrieved from http://nidrees.kau.edu.sa/Files/320/Researches/51638_21773.pdf

Altbach, P. G. (2004). Globalisation and the university: Myths and realities in an unequal world. Tertiary Education \& Management, 10(1), 3-25. http://dx.doi.org/10.1080/13583883.2004.9967114

Baas, M. (2006). Students of migration: Indian overseas students and the question of permanent residency. People and Place, 14(1), 8-23.

Bahgat, G. (1999). Education in the Gulf monarchies: Retrospect and prospect. International Review of Education, 45(2), 127-136. http://dx.doi.org/10.1023/A:1003610723356

Barber, M., Mourshed, M., \& Whelan, F. (2007). Improving education in the Gulf. The McKinsey Quarterly, Special edition, 38-47.

Bartlett, J. E., Kotrlik, J.W., \& Higgins, C. (2001).Determining appropriate sample size for survey research. Information Technology, Learning and Performance Journal, 19(1), 43-50.

Baruch, Y., Budhwar, P. S., \& Khatri, N. (2007). Brain drain: Inclination to stay abroad after studies. Journal of World Business, 42(1), 99-112. http://dx.doi.org/10.1016/j.jwb.2006.11.004

Bashraheel, L. (2013, March 11). Scholarship students: Big dreams, slow change. Saudi Gazette. Retrieved from http://www.saudigazette.com.sa/index.cfm?method=home.regcon\&contentid=20130311156300

Batterjee, M. A. A. (2010). A phenomenology study examining partial breast-feeding in the Kingdom of Saudi Arabia. Retrieved from http://search.proquest.com/docview/305121088?accountid=15099

BBC News Middle East (2013). Saudi Arabia king swears in first women on Shura Council, 20 February. Retrieved from http:/www.bbc.com/news/world-middle-east-21516955

Bin Taleb, A. (2013). The upcoming oil: why Saudis invest in higher education and scholarship. Riyadh: King Fahd National Library.

Bukhari, F., \& Denman, B. (2013). Student scholarships in Saudi Arabia: Implications and opportunities for overseas engagement. In L. Smith \& A. Abouammoh (Eds.), Higher education in Saudi Arabia: Achievements, Challenges and Opportunities (pp. 151-158). Dordrecht: Springer. http://dx.doi.org/10.1007/978-94-007-6321-0_14

Clary, C., \& Karlin, M. E. (2011).Saudi Arabia's reform gamble. Survival, 53(5), 15-20. http://dx.doi.org/10.1080/00396338.2011.621619

Coleman, I. (2012). Saudi Arabia's study program. Retrieved from http://blogs.cfr.org/coleman/2012/06/26/saudi-arabias-study-abroad-program/\#

Commander, S., Kangasniemi, M., \& Winters, L. A. (2004). The brain drain: Curse or boon? A survey of the literature. In R. E. Baldwin \& L. A. Winters (Eds.), Challenges to globalization: Analyzing the economics (pp. 235-278). Chicago: University of Chicago Press.

Conrad, P. (1990). Qualitative research on chronic illness: A commentary on method and conceptual development. Social Science \& Medicine, 30(11), 1257-1263. http://dx.doi.org/10.1016/0277-9536(90)90266-U 
Davis, N., \& Hayashi, C. (2007). The Gulf Cooperation Council (GCC) countries and the world: Scenarios to 2025: Implications for competitiveness. In The Arab World competitiveness report 2007 (pp. 129-141). Geneva: World Economic Forum.

Denman, B., \& Hilal, K. (2011). From barriers to bridges: An investigation of Saudi student mobility (2006-2009). International Review of Education, 57(3/4), 299-318. http://dx.doi.org/10.1007/s11159-011-9221-0

Dustmann, C., Fitzenberger, B., \& Machin, S. (2007). The economics of education and training. Empirical Economics, 32(2), 255-260. http://dx.doi.org/10.1007/s00181-006-0113-2

Fawcett, L. (Ed.). (2013). International relations of the Middle East. Oxford: Oxford University Press.

Feng, Y. (2001). Political freedom, political instability, and policy uncertainty: A study of political institutions and private investment in developing countries. International Studies Quarterly, 45(2), 271-294. http://dx.doi.org/10.1111/0020-8833.00191

Gallarotti, G. M. (2013). Smart development: Saudi Arabia's quest for a knowledge economy. Division II Faculty Publications, Paper 128.

Gause, F. G. (1994). Oil monarchies: Domestic and security challenges in the Arab Gulf states. New York: Council on Foreign Relations Press.

Gause, G. (1997). The Gulf conundrum: Economic change, population growth, and political stability in the GCC states. The Washington Quarterly, 20(1), 142-165. http://dx.doi.org/10.1080/01636609709550234

Gause, G. (2002). Be careful what you wish for: The future of U.S.-Saudi relations. World Policy Journal, 19(1), $37-50$.

GulfTalent.com. (2012). Employment and salary trends in the Gulf. Retrieved from http://www.gulftalent.com/home/Employment-and-Salary-Trends-in-the-Gulf-2012-Report-33.html

Hall, T. R. (2013). Saudi male perceptions of study in the United States: An analysis of King Abdullah Scholarship program participants (Doctoral dissertation). Retrieved from the Research and Creative Activity Database of WKU (WKU No. 50).

Heyn, M. E. (2013). Experiences of male Saudi Arabian international students in the United States (Doctoral dissertation). Western Michigan University. Paper 176 retrieved from http://scholarworks.wmich.edu/dissertations/167

Hilal, K. T., \& Denman, B. D. (2013). Education as a tool for peace? The King Abdullah Scholarship programme and perceptions of Saudi Arabia and UAE post 9/11. Higher Education Studies, 3(2), 24-40. http://dx.doi.org/10.5539/hes.v3n2p24

Holden, J. D. (2001). Hawthorne effects and research into professional practice. Journal of Evaluation in Clinical Practice, 7(1), 65-70. http://dx.doi.org/10.1046/j.1365-2753.2001.00280.x

Inglehart, R., Foa, R., Peterson, C., \& Welzel, C. (2008). Development, freedom, and rising happiness: A global perspective (1981-2007). Perspectives on Psychological Science, 3(4), 264-285. http://dx.doi.org/10.1111/j.1745-6924.2008.00078.x

Institute of International Education. (2014).Open Doors Report on International Educational Exchange. Retrieved from http://www.iie.org/opendoors

Kapiszewski, A. (2006). Arab versus Asian migrant workers in the GCC countries. Paper presented at the United Nations Expert Group Meeting on International Migration and Development in the Arab region. Population Division Department of Economic and Social Affairs United Nations Secretariat, Beirut, 15-17 May 2006.

Knickmeyer, E. (2012, November 8). Saudi students flood in as U.S. reopens door. The Wall Street Journal. Retrieved from http://online.wsj.com/article/SB10001424052702304830704577492450467667154.html

Kusow, A. M. (2003). Beyond indigenous authenticity: Reflections on the insider/outsider debate in immigration research. Symbolic Interaction, 26(4), 591-599. http://dx.doi.org/10.1525/si.2003.26.4.591

Mahroum, S. (1999). Competing for the highly skilled: Europe in perspective. Science and Public Policy, 26(1), 17-25. http://dx.doi.org/10.3152/147154399781782608

Mazi, A. A. \& Abouammoh, A. M. (2009). Development of higher education in the Kingdom of Saudi Arabia: Trends and strategies. Paper presented at the Global Higher Education Forum GHEF09 on 13-16 December, 2009, Penang, Malaysia. 
Meo, S. (2013, January 4). Saudi Arabia's 'golden age of learning' under King Abdullah. Arab News. Retrieved from http://www.arabnews.com/saudi-arabia's-'golden-age-learning'-under-king-abdullah

Ministry of Finance. (2014). Kingdom of Saudi Arabia. Retrieved from http://www.mof.gov.sa/Arabic/DownloadsCenter/Pages/Budget.aspx

Ministry of Higher Education. (2014). King Abdullah Scholarship Programme, Introduction. Retrieved from http://www.mohe.gov.sa/en/studyaboard/King-Abdulla-hstages/Pages/introduction-a.aspx

Mitchell, J. (2010). Political and socioeconomic transformation in the GCC: Image and reality. History Compass, 8(3), 275-302. http://dx.doi.org/10.1111/j.1478-0542.2009.00663.x

Nevo, J. (1998). Religion and national identity in Saudi Arabia. Middle Eastern Studies, 34(3), 34-53. http://dx.doi.org/10.1080/00263209808701231

Ottaway, D. (2012). Saudi Arabia's race against time. Retrieved from http://www.wilsoncenter.org/sites/default/files/saudi_arabias_race_against_time.pdf

Pang, T., Lansang, M. A., \& Haines, A. (2002). Brain drain and health professionals: A global problem needs global solutions. British Medical Journal, 324(7336), 499-500. http://dx.doi.org/10.1136/bmj.324.7336.499

Profile: Saudi Arabia: Head of state, prime minister: King Abdullah Bin-Abd-al-Aziz Al Saud. (2013, Feb 20). BBC News. Retrieved from http://www.bbc.co.uk/news/world-middle-east-14703478

Rizvi, F. (2005). Internationalization of curriculum: A critical perspective. In M. Hayden, J. Levy \& J. Thompson (Eds.), The SAGE handbook of research in international education (pp. 390-403). London: Sage.

Royal Embassy of Saudi Arabia in Washington DC. (2013). Saudi Arabia, history: King Abdullah bin Abdulaziz. Retrieved from http://www.saudiembassy.net/about/countryinformation/history/http://www.saudiembassy.net/about/KingAbdull ah.aspx

Solimano, A. (Ed.). (2008). The international mobility of talent: Types, causes, and development impact. Oxford: Oxford University Press. http://dx.doi.org/10.1093/acprof:oso/9780199532605.001.0001

Straubhaar, T. (2000). International mobility of the highly skilled: Brain gain, brain drain or brain exchange. $H W W A$ Discussion Paper, No. 88. Hamburg: Hamburg Institute of International Economics.

SUSRIS [Saudi-US Relations Information Service] (2012). King Abdullah Scholarship Program: The Saudi Arabian Educational Youth Stride, $30 \quad$ July. $\quad$ Retrieved from http://susris.com/2012/07/30/king-abdullah-scholarship-program-the-saudi-arabian-educational-youth-stride/

The Economist Intelligence Unit. (2009a). The GCC in 2020: Outlook for the Gulf and the global economy. A report from the Economist Intelligence Unit Sponsored by the Qatar Financial Centre Authority. Retrieved from http://graphics.eiu.com/marketing/pdf/Gulf2020.pdf

The Economist Intelligence Unit. (2009b). The GCC in 2020: The Gulf and its People. A report from the Economist Intelligence Unit Sponsored by the Qatar Financial Centre Authority.Retrieved from http://graphics.eiu.com/upload/eb/Gulf2020part2.pdf

Thomas, D. (2013, January 18). How has Saudi Arabia's KASP impacted the sector? The Pie News. Retrieved from http://thepienews.com/analysis/how-has-saudi-arabias-kasp-impacted-the-sector/

Tremblay, K. (2002). Student mobility between and towards OECD countries: A comparative analysis. In OECD Proceedings, International mobility of the highly skilled (39-67). Paris: OECD Publications.

United Nations Development Program. (2014). International Human Development Indicators. 2014 Human Development Report. Retrieved January 6, 2015, from http://hdr.undp.org/en/countries

Väyrynen, R. (1984). Regional conflict formations: An intractable problem of international relations. Journal of Peace Research, 21(4), 337-359. http://dx.doi.org/10.1177/002234338402100403

Verbik, L., \& Lasanowski, V. (2007). International student mobility: Patterns and trends. World Education News and Reviews, 20(10), 1-16.

World Bank. (2015). Saudi Arabia Data. Retrieved January 6, 2015, from data.worldbank.org/country/saudi-arabia

Zeigler, L. (2012, July 25). The Saudi Cultural Mission's new headquarters. Retrieved from http://susris.sustg.org/2012/07/25/the-saudi-cultural-missions-new-headquarters/

Zweig, D. (1997). To return or not to return? Politics vs. economics in China's brain drain. Studies in Comparative International Development, 32(1), 92-125. http://dx.doi.org/10.1007/BF02696307 